\title{
Website quality of Malaysian Technical University (MTUN)
}

\author{
Lim Pui Jie ${ }^{1}$, Rohaizan Ramlan², Rohayanti Hassan ${ }^{3}$, Rashidah Omar ${ }^{4}$, Chan Shau Wei ${ }^{5}$ \\ 1,2,5 Faculty of Technology Management and Business, Universiti Tun Hussein Onn Malaysia, Malaysia \\ ${ }^{3}$ Faculty of Computing, Universiti Teknologi Malaysia, Malaysia \\ ${ }^{4}$ Department of Computer Science, Universiti Teknologi MARA, Malaysia
}

\begin{tabular}{l} 
Article Info \\
\hline Article history: \\
Received Jan 10, 2019 \\
Revised May 1, 2019 \\
Accepted Jul 1, 2019 \\
\hline
\end{tabular}

Keywords:

AHP

Diagnostic tools

Website quality

\begin{abstract}
University website is the platform for university to interact with people. It is also an interphase for people to infer and getting known about the university. In addition, quality of the university website is vital to let people get positive response to the university. Therefore, university website should be evaluated for better performance. This study evaluate website of Malaysian Technical University (MTUN) on year of 2016 based on the criteria selected using online web diagnostics tools. There are nine criteria selected to measure the website; load time, response time, page rank, traffic, design optimization, page size, number of items, markup validation and broken link. The result shows website of UMP performed better in design optimization, page rank and markup validation. Meanwhile, UTHM performed in page rank, load time and page size. UTEM excellences in response time, number of items and broken link. Lastly, UniMAP performed in traffic criteria only. However, the (MTUN) University website is almost not meets with the criteria that selected with the quality standard that have been suggested.
\end{abstract}

Copyright $\odot 2020$ Institute of Advanced Engineering and Science. All rights reserved.

\section{Corresponding Author:}

Rohaizan Ramlan,

Faculty of Technology Management and Business,

Universiti Tun Hussein Onn Malaysia, Malaysia.

Email: rohaizan@uthm.edu.my

\section{INTRODUCTION}

Website initially was static with only have a plain hypertext markup language to structure the information [1]. Evolution then start with the web containing text, images, audio and video [2], user can interact directly using keyword search tools with social web or interactive content [3]. After that, it continues evolve to dynamic web page that generated by a server-side program or script [4]. There have four categories can be classified by their use purposes of website, which are communication, information gathering, entertainment and commerce or online transaction [5]. University web pages often contain important information about academic resources, campus event, and administrative policies, other than that, it also provide access to university services such as the library, campus bookstore and course registration system that play a crucial role in the day to day lives of postsecondary students [6]. Since university website is a platform between student and University to interact, the performance of the university website should get attention from all parties in order to have a good platform to delivery information effectively.

There are various studies of website evaluation. One of the study was by Hasan [7] proposes the general criteria for evaluating the quality of any website by different dimensions of the criteria regardless of the type of service that it offers. There also have a study about quality of website structure measured based on the navigability, average number of clicks and structural complexity [2]. Yee et, al [8] using web diagnostics tool that available free to evaluate dynamic web pages. Besides that, website quality evaluation also can based on search engine queries using web rank position algorithm [9]. The website evaluation can be approached from users, website designer/administrator or both together [10]. However website evaluation 
from user's perspective usually focus on the factors of successful websites, while, website evaluation from website designer/administrator will more focus on the web usability and accessibility [11].

Since choosing the best website is a difficult task and human judgement may be imprecise to measure the each quality dimension of the website [12], there is necessity for some evaluation tools to evaluate the performance of the website. Website evaluation tool can be divided by two methods, which were automated and non-automated tools. Non-automatic can defined as method "performed by human factors specialists" [13] and can be done in user testing approach, heuristic testing approach or both approaches [12]. Meanwhile, an automated evaluation tool is software that automates the collection of interface usage data (automated capture) or the identification (automated analysis) and the resolution (automated critique) of potential problems [14] such as WatchFire Bobby, W3C HTML Validator, WebTango and others. Automated evaluation tools can be found off-line and web-based [15]. Zahran et., al [16] suggested that, to discover most of website potential usability problems, automatic tool is a useful complement in this situation. Kaur et,. al [17] also used automated tools to validate the Punjab's universities website usabilities.

The measurement criteria used, derived from literature review since 2008 to 2016 that table as matrix frequency. The nine criteria are load time, response time, page rank, traffic, design, size, number of items, markup validation and broken link as shown in Table 1.

If the website can achieved each of the quality standard, the ranking of website will be higher. Research studied by IBM [25] that related to the standard of the website performance should be achieved or followed to perceive as a good quality website. There are four tested factor in the study as shown in Table 2. In addition, there is also a quality standard for load time set by Malaysia Digital Economy Corporation $(\mathrm{MDeC})$ and Malaysia Administrative Modernisation and Management Planning Unit (MAMPU) in Provider- Based Evaluation (ProBE) 2016. The target load time set as 5 seconds and below for government website including university website.

Based on the webometric ranking of university website, the analysis is to motivate those institutions and scholars to have a web presence that reflect accurately their activities. The webometric website also stated that if the web performance of an institution is below the expected position according to their academic excellence, university authorities should reconsider their web. Recently, a few study have been done about the evaluation of "Research University (RU)" website in Malaysia based on webometric [11], [12]. However, there are lacks of study about MTUN website quality. Hence, this study evaluate the performance of MTUN website on year of 2016 based on the criteria selected using online web diagnostics tools.

Table 1. The Criteria Used for Measurement and the Explanation for Each



Table 2. Standard of the Website Performance by IBM and ProBE 2016

\begin{tabular}{cc}
\hline Tested factor & Quality Standard \\
\hline Average Sever Response Time & $<0.5$ seconds \\
Number of Components Per Page & $<20$ objects \\
& IBM \\
Webpage Loading Time ProBE 2016 & $<30$ seconds \\
Webpage Size in Byte & 5 seconds and below \\
\hline
\end{tabular}

\section{RESEARCH METHOD}

This research applied multiple case studies. Since the data obtained from web diagnostic tool based on the criteria from four different (MTUN) university website. The primary data collected through web diagnostic tools as shown in Table 3 for 100 times at different period. 
Table 3. The Online Web Diagnostic Tools for Data Collection

\begin{tabular}{ll}
\hline Criteria & Web Diagnostic Tools \\
\hline Load time & Tools.pingdom.com \\
Response Time & www.websitepulse.com \\
Page Rank & www.prchecker.info \\
Traffic & www.Similarweb.com \\
Design Optimization & Tools.pingdom.com \\
Page Size & Tools.pingdom.com \\
Number of items & Tools.pingdom.com \\
Markup Validation & Validator.w3.org \\
Broken Link & Validator.w3.org/checklink \\
\hline
\end{tabular}

\section{RESULTS AND ANALYSIS}

Table 4 shows most of the (MTUN) university website cannot meet the criteria for a high-quality website. For the load time, the entire (MTUN) university website fulfills the IBM Standard which stated that load time should not more than 30 seconds. However, based on target criteria of MDeC and MAMPU, (MTUN) university website are not fulfil the standard set which is 5 second and below. UTHM displays the fastest loading time, followed by the UMP with 7.67 seconds, UniMAP with 8.31 seconds and lastly UTeM with 12.56 seconds. The load time is important criterion for the website because it may affect the users and abandon the website if the website takes a long time to load the web pages.

For the response time, all the (MTUN) university website is not meet the IBM standard which stated that response times should not more than 0.5 seconds to get a high-quality website. This is because all the (MTUN) university exceed the value that been standardized by IBM. The fastest response time take by university website among the four is the UTeM website with 2.62 seconds, followed by the UTHM website with 3.91 seconds, UMP with 4.69 seconds and lastly UniMAP with 6.68 seconds. Response times also an important criterion that should be evaluated in website in order to get a quality website.

For the page rank, it uses the rank of 1 to 10 to determine the page's relevance or importance. The most popular website will have a page rank of 10 and the least popular website will have a page rank of 0. UTHM and UMP had the page rank of 6, while the UniMAP and UTeM had the page rank of 0 . Thus, it showed UniMAP and UTeM website not achieved a high-quality website. UniMAP website has the higher traffic which meant that the highest quality of website with 13971 among the (MTUN) university website. Then followed by the UMP website with 12907, UTHM with 12691 and lastly was the UTeM with the least traffic which meant that the lowest quality with 6027.

Design Optimization evaluated in percentage form, from 0 to $100 \%$. The higher the percentage means that the more quality of the website since good design optimization can make the website perform well and faster by reduce the time to access the website. UMP has the highest percentage of $87 \%$ followed by the UTHM and UTeM with the same percentage of 73\% and the lowest percentage is the UniMAP with 55\%.

Table 4. Result of Criteria for (MTUN) University Website

\begin{tabular}{llcccc}
\hline \multicolumn{1}{c}{ Criteria } & Unit of Measurement & UTHM & UniMAP & UMP & UTeM \\
\hline Load time (<30 seconds / 5 seconds ) & Seconds & 6.76 & 8.31 & 7.67 & 12.56 \\
Response Time ( < 0.5seconds) & Seconds & 3.91 & 6.68 & 4.69 & 2.62 \\
Page Rank (more higher good) & Number ( out of 10) & 6 & 0 & 6 & 0 \\
Traffic (more higher good) & Number & 12691 & 13971 & 12907 & 6027 \\
Design Optimization ( more higher good) & Percentage & 73 & 55 & 87 & 73 \\
Page Size (<64Kb) & Kb/ seconds & 13926 & 25141 & 28320 & 20455 \\
Number of items (<20 items) & Number & 104 & 155 & 141 & 76 \\
Markup Validation (Zero error) & Number & 80 & 78 & 48 & 60 \\
Broken Link (zero broken link) & Number & 9 & 13 & 27 & 2 \\
\hline
\end{tabular}

Page size that recorded in kilobytes per seconds for (MTUN) university website of page size exceeded the IBM Standard. The closer with the IBM standard of the page size is the UTHM website with $13926 \mathrm{~Kb} /$ seconds, followed by the UTeM with $20455 \mathrm{~Kb} /$ seconds, UniMAP with $25141 \mathrm{~Kb} /$ seconds and lastly UMP with $28320 \mathrm{~Kb} /$ seconds.

Number of items can be defined as number of components per page that should not exceed 20 objects in order to have a quality website. UTeM website has lowest number of items with 76 , followed by the UTHM with 104 items, UMP with 141 items and UniMAP with 155 items. It shows that all four (MTUN) university website also not meet the IBM Standard for number of components per pages.

Markup validation valid when the process of verifying of a document of the website follows the rules for the languages which is lower number of error been detected in the process, the higher the quality of 
the website. UMP website with the least number of 48 markup error was the most quality university website, followed by the UTeM website with 60 markup error, UniMAP website with 78 markup error and lastly UTHM website with the highest number of markup error of 80 . Thus, there are no one (MTUN) university website valid and passed the validation process.

Broken link on the web page for UTeM university website shown the most quality of the website with only 2 error of link occurs, followed by the UTHM website with 9 error, UniMAP with 13 error and lastly UMP with 27 error of link occur in the website which shown the poor quality of website since the highest the number of broken link, the poor quality of the website. The result shows website of UMP performed better in design optimization, page rank and markup validation. Meanwhile, UTHM performed in page rank, load time and page size. UTEM excellences in response time, number of items and broken link. Lastly, UniMAP performed in traffic criteria only.

\section{CONCLUSION}

Some limitation or difficulties occurred during this study such as finding the free online diagnostic tools. Numerous online diagnostic tools in market required paying and limited usages. Thus, it takes some of the time to search and find the suitable one. Furthermore, the suggestion by Provider-Based Evaluation (Probe) 2016 for collected load time in peak hour where 10 am to $1 \mathrm{pm}$ or $2 \mathrm{pm}$ to $4 \mathrm{pm}$ can be applied since the peak hour demonstrate the effectiveness of the website. In a nutshell, the objective of this study which is to evaluate website quality of Malaysian Technical University (MTUN) on year of 2016 based on the criteria selected using online web diagnostics tools is achieved with UTHM website performed in page rank, load time and page size. Meanwhile, UMP website performed better in design optimization, page rank and markup validation. UTEM excellences in response time, number of items and broken link. Lastly, UniMAP performed in traffic criteria only. However, the (MTUN) University website is almost not meets with the criteria that selected with the quality standard that have been suggested.

\section{ACKNOWLEDGEMENTS}

This research was supported by research fund at Research Management Centre (RMC), Universiti Tun Hussein Onn Malaysia (UTHM) (vot : E15501).

\section{REFERENCES}

[1] Bahry1\&2, F. D. S. et al., "Website evaluation measures, website user engagement and website credibility for Municipal website", Arpn J. of Engineering and Applied Sciences, 10(23), pp. 18228-18238, 2015.

[2] Sreedhar, G. et al., "Measuring Quality Of Web Site Navigation", Journal of Theoretical \& Applied Information Technology, 14, pp. 80-86, 2010

[3] Jain, A., and Ramachandran, S. "Using resource load times in ranking search results." U.S. Patent 8,645,362, issued February 4, 2014.

[4] G. Saibaba, S. Prasanth Vaidya M and Ramani A.V, "Developing an Userfriendly Online Shopping Web-Site", Indonesian Journal of Electrical Engineering and Computer Science (IJEECS), 12(3), 1126-1131, 2018.

[5] Lee, S., and Koubek, R. J., "Understanding user preferences based on usability and aesthetics before and after actual use", Interacting with Computers, 22(6), pp. 530-543, 2010.

[6] Kane, S. K. et al., "A web accessibility report card for top international university web sites", In Proceedings of the 2007 international cross-disciplinary conference on Web accessibility (W4A) pp. 148-156, May, 2007.

[7] Hasan, L., and Abuelrub, E., "Assessing the quality of web sites", Applied Computing and Informatics, 9(1), 11-29, 2011.

[8] Yee, T.B, Ramlan, R., Hassan, R., Shukri, SRM, Mokhtar, R. "The Evaluation of Third Party Hotel Booking Website Performance Using Analytic Hierarchy Process (AHP)." Journal of Advanced Research in Dynamical and Control Systems, 10(7) 426-431, 2018.

[9] Chandran, M and Ramani A.V, "Website Quality Evaluation Based on Search Engine Queries using Web Rank Position Algorithm (WRPA)", Indonesian Journal of Electrical Engineering and Computer Science (IJEECS), 4(1), No. 1, 224-230, 2016.

[10] Sayar, C. and Wolfe, S. (2007) "Internet banking market performance: Turkey versus the UK", International Journal of Bank Marketing, Vol. 25, pp.122-141.

[11] Dominic, P. D. D., et al., "University website quality comparison by using non-parametric statistical test: a case study from Malaysia”. International Journal of Operational Research, 16(3), pp. 349-374, 2013.

[12] Dominic, P. D. D., and Khan, H., "Performance measure of airline websites using analytical hierarchy process \& analytical hierarchy process", In Control System, Computing and Engineering (ICCSCE), 2014 IEEE International Conference on, pp. 530-535, November, 2014.

[13] Ivory, M. Y., “Automated Web Site Evaluation: Researchers' and Practioners' Perspectives”. Springer Science \& Business Media, Vol. 4, 2013. 
[14] Ivory, M. Y., and Hearst, M. A., "The state of the art in automating usability evaluation of user interfaces" $A C M$ Computing Surveys (CSUR), 33(4), pp. 470-516, 2001.

[15] Brajnik, G., "Automatic web usability evaluation: what needs to be done", In Proc. Human Factors and the Web, 6th Conference. 2000.

[16] Zahran, D. I., Al-Nuaim, H. A., Rutter, M. J., \& Benyon, D. "A comparative approach to web evaluation and website evaluation methods", International Journal of Public Information Systems, 10(1), 2014.

[17] Kaur, S., Kaur, K., \& Kaur, P. "An empirical performance evaluation of Universities Website", International Journal of Computer Applications, 146(15), 10-16, 2016.

[18] Plumley, G., "Website design and development: 100 questions to ask before building a website", John Wiley \& Sons. 2010.

[19] Cambridge Dictionaries Online. Cambridge University Press, Retrived from http://dictionary.cambridge.org/.2016.

[20] Kent, P., "Search Engine Optimization For Dummies. Indianapolis", Indiana: Wiley Publishing, Inc., 2004.

[21] Jenkins, S., "Web Design All-in-One for Dummies. Indianapolis", Indiana: Wiley Publishing, Inc., 2009.

[22] Mittal, H., et al., "Analysis and modelling of websites quality using technique", In 2012 Second International Conference on Advanced Computing \& CommunicationTechnologies, pp.10-15, January, 2012.

[23] Connolley.M \& Smith.K., Iteracy Retrived from https://www.iteracy.com/resources/item/size-and-layout-of-a-webpage?page=size-and-layout-of-a-web-page, 2007.

[24] “W3C Markup Validation Service”, Retrived from https://validator.w3.org/about.html, 1994-2013.

[25] Amerson, M., et al., "Design for performance: analysis of download times for page elements suggests ways to optimize", 2001 [online] http://www.ibm.com/developerworks/websphere/library/techarticles/hipods/perform.

\section{BIOGRAPHIES OF AUTHORS}

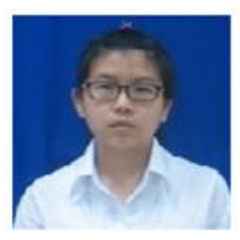

Lim Pui Jie She obtained her Bachelor Degree from Faculty of Technology Management and Business, UTHM in 2017. Her research area is in web measurement.

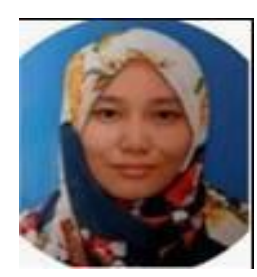

Rohaizan Ramlan is a senior lecturer in Operation Management at the Faculty of Technology Management and Business, UTHM. She pursued Manufacturing Information Technology studies at Masters level in UTM in 2005. Her bachelor degree is in Computer Science BSc. (Hons.) in UTM. Rohaizan has multidisciplinary research interests that encompass production and operation management and decision making.



Rohayanti Hassan is a senior lecturer at School of Computing, UTM. She got her PhD in Computer Science (Bioinformatics) at Universiti Teknologi Malaysia in 2011. She also active in other research areas, for instance, software testing, software requirements, image processing, text mining and machine learning.

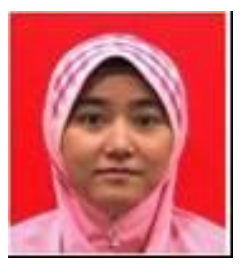

Rashidah Omar is a lecturer at Computer Science Department, UiTM Johor. She is currently persue her PhD in Information System at Universiti Teknologi Malaysia. Her research interests are in Information Science and Model-Driven Development.

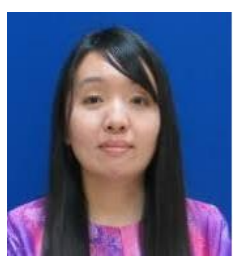

Chan Shau Wei is a lecturer at Faculty of Technology Management and Business, UTHM. She obtained her PhD in Education (Mathematic) at Universiti Teknologi Malaysia in 2014. Her research interest is in applied mathematic and education area. 